\title{
Apoio a projetos de divulgação científica: análise de edital realizado pela Fundação Oswaldo Cruz
}

\author{
Financial support for science communication projects: analysis of the call \\ carried out by the Oswaldo Cruz Foundation
}

\section{Apoyo a proyectos de divulgación de la ciencia: análisis de convocatoria realizada por la Fundación Oswaldo Cruz}

\author{
Luisa Massarani $i^{1,2, a}$ \\ luisa.massarani6@gmail.com | https://orcid.org/o000-0002-5710-7242
}

Willian Vieira de Abreu ${ }^{3, b}$

willian.fisico@gmail.com | https://orcid.org/o000-0002-6685-2754

Jessica Norberto Rocha ${ }^{2,4, c}$

jessicanorberto@yahoo.com.br | https://orcid.org/0000-0002-9754-3874

\footnotetext{
${ }^{1}$ Fundação Oswaldo Cruz, Casa de Oswaldo Cruz. Rio de Janeiro, RJ, Brasil.

2 Instituto Nacional de Comunicação Pública da Ciência e Tecnologia. Rio de Janeiro, RJ, Brasil.

${ }^{3}$ Universidade Federal do Rio de Janeiro. Rio de Janeiro, RJ, Brasil.

${ }^{4}$ Fundação Centro de Ciências e Educação Superior a Distância do Estado do Rio de Janeiro. Rio de Janeiro, RJ, Brasil.
}

a Doutorado em Bioquímica Médica pela Universidade Federal do Rio de Janeiro.

b Mestrado em Ciência e Tecnologia Nucleares pelo Instituto de Engenharia Nuclear.

c Doutorado em Educação pela Universidade de São Paulo.

\section{Resumo}

Este artigo objetiva analisar, por meio de métodos quantitativos e qualitativos e análise de conteúdo, as 145 propostas submetidas ao edital de apoio a projetos de divulgação científica, realizado pela Fundação Oswaldo Cruz, em 2018, visando compreender a demanda existente e dar subsídios para a elaboração de uma política institucional. Foram definidas categorias de análise, tendo em vista a identificação e caracterização do perfil dos proponentes e projetos. Os resultados indicam que, embora haja concentração de projetos na região Sudeste, profissionais de nove estados brasileiros participaram da convocatória, sendo $63 \%$ das propostas submetidas por mulheres. Apenas $40 \%$ dos projetos previam ação/estratégia de avaliação e somente $7 \%$ mencionaram ações de acessibilidade, tema prioritário na Fiocruz. Destacamos, por fim, a necessidade de oferecer frequentemente editais desse tipo, associados ao desenvolvimento de programas e capacitação da comunidade da Fiocruz para estabelecer o diálogo com a sociedade, de forma diversificada, abrangente, acessível e inclusiva.

Palavras-chave: Divulgação científica; Engajamento público na ciência; Fundação Oswaldo Cruz; Editais; Popularização da ciência. 


\begin{abstract}
This paper aims to analyze, through quantitative and qualitative methods and content analysis, the 145 proposals submitted to the call for supporting science communication projects, carried out by the Oswaldo Cruz Foundation, in 2018, intending to provide a better understanding of the existing demand and to contribute to the elaboration of an institutional policy. Categories to be analyzed in order to map the profile and characteristics of the proposals and proponents were defined. The results indicate that, although there is a concentration of projects in the Southeast region, professionals from nine Brazilian states participated in the call, being $63 \%$ of them women. Only $40 \%$ of the projects proposed evaluation actions and only $7 \%$ mentioned accessibility strategies, a priority issue at Fiocruz. Finally, we emphasize the need of frequently offering this kind of calls, associated with the training of scientists and of the Fiocruz community to establish dialogue with society in a diversified, comprehensive, accessible and inclusive way.
\end{abstract}

Keywords: Science communication; Public engagement with science; Oswaldo Cruz Foundation; Bids; Science popularization.

\title{
Resumen
}

Este artículo objetiva analizar, por medio de métodos cuantitativos y cualitativos y análisis de contenido, los 145 proyectos sometidos a la convocatoria para apoyo a proyectos de divulgación científica, realizado por la Fundación Oswaldo Cruz, en 2018, buscando proveer subsidios para comprender la demanda existente y contribuir a la elaboración de una política institucional. Se definieron categorías de análisis, teniendo en cuenta la identificación y caracterización del perfil de los proponentes y proyectos. Los resultados indican que, aunque hay concentración de proyectos en la región sudeste, profesionales de nueve estados brasileños participaron de la convocatoria, siendo el 63\% de las propuestas sometidas por mujeres. Sólo el $40 \%$ de los proyectos preveía acción/estrategia de evaluación y sólo el 7\% mencionó acciones de accesibilidad, tema prioritario en la Fiocruz. Por último, destacamos la necesidad de ofrecer a menudo convocatorias de este tipo, asociada al desarrollo de programas y acciones de capacitación de los científicos y de la comunidad de Fiocruz para establecer el diálogo con la sociedad, de forma diversa, completa, accesible e inclusiva.

Palabras clave: Divulgación de la ciencia; Apropiación social en la ciencia; Fundación Oswaldo Cruz; Convocatorias; Popularización de la ciencia.

Contribuição dos autores:

Concepção e desenho do estudo: todos os autores.

Aquisição, análise ou interpretação dos dados: todos os autores.

Redação do manuscrito: todos os autores.

Revisão crítica do conteúdo intelectual: todos os autores.

Declaração de conflito de interesses: não há.

Fontes de financiamento: não houve.

Considerações éticas: não há.

Agradecimentos/Contribuições adicionais: Manoel Barral Netto.

Histórico do artigo: submetido: 24 nov. 2018 | aceito: 07 fev. 2019 | publicado: 28 jun. 2019.

Apresentação anterior: não houve.

Licença CC BY-NC atribuição não comercial. Com essa licença é permitido acessar, baixar (download), copiar, imprimir, compartilhar, reutilizar e distribuir os artigos, desde que para uso não comercial e com a citação da fonte, conferindo os devidos créditos de autoria e menção à Reciis. Nesses casos, nenhuma permissão é necessária por parte dos autores ou dos editores. 


\section{Introdução}

O relatório influente elaborado no escopo da Royal Society, na Inglaterra, intitulado The Public Understanding of Science, também conhecido por Bodmer Report, convocou, em 1985, cientistas a aprimorar seu diálogo com a sociedade, uma vez "que claramente era parte da responsabilidade profissional de cada cientista promover a compreensão pública da ciência”. Segundo o relatório, o público não era suficientemente positivo sobre a ciência e a tecnologia, e isso poderia abalar a Ciência como instituição. Assim, para promover uma mudança de atitude era necessário relacionar conhecimento, educação e comunicação pública e, para isso, seus autores recomendaram fortemente que "todas as instituições e organizações científicas desenvolvessem procedimentos de boas relações públicas”.

Com esse objetivo, segundo Steve $\mathrm{Miller}^{2}$, o relatório fez recomendações que levaram à implantação de atividades imediatas no país, por exemplo, a criação de um comitê voltado para a compreensão pública da ciência, e ao incentivo à mídia para abordar questões sobre o tema, por meio dos jornais, rádio e TV; a criação de ações diversas de divulgação científica, com ampla cobertura midiática, dentre elas, eventos como semanas de ciência, engenharia e tecnologia - em que a comunidade científica deveria levar a seu público o que estava fazendo nos laboratórios; o financiamento de pesquisas para medir a compreensão pública da ciência e o conhecimento científico e tecnológico do público, além de conceber estratégias para monitorar as atitudes da população inglesa perante a ciência ${ }^{2,3}$. Esses processos intensificaram ainda mais as ações em prol da divulgação científica na Inglaterra nos anos 90 e incentivaram outros países.

Apesar de a retórica ser baseada na defesa e no diálogo, muitos esforços de divulgação científica nos anos finais do século XX ainda tinham como foco a ideia dos déficits de conhecimento científicos da sociedade, e, por isso, esse formato recebeu várias críticas - como não considerar o papel ativo dos diversos públicos, suas competências e demandas ${ }^{4,5}$. A importância de se proceder a uma ação comunicativa que levasse em conta sua complexidade e envolvesse diversos atores e estruturas sociais foi, então, uma proposta, já que se acreditava que o aprimoramento da cultura científica não implica apenas uma via de mão única na transmissão do conhecimento. Para Miller², pesquisas na área da divulgação científica mostraram que a ciência poderia ser, ao mesmo tempo, "socialmente construída" e um 'conhecimento confiável”’”.

A partir disso, emergiram propostas de outros modelos de divulgação científica, chamados de 'dialógicos', que tinham como paradigma a 'ciência e sociedade' para determinar não só investigações, mas políticas públicas e ações de educação e divulgação da ciência. Bauer, Allum e Miller ${ }^{6}$ destacam que a publicação de outro relatório pelo governo britânico, o Science and Technology 7 , apresentado em 2000, foi outro momento significante para a divulgação científica no país, já que ele exigia uma melhoria do diálogo entre ciência e sociedade, por meio de uma política aberta de informação ao público e de debates sobre os riscos e incertezas das aplicações científico-tecnológicas ${ }^{2,7}$.

A máxima passa a ser, assim, a de restaurar a confiança da população na ciência e seus produtos e na produção do conhecimento, a partir da deliberação e da participação pública por meio da implantação de diferentes atividades, a fim de facilitar e dar voz às audiências nas etapas iniciais da implementação dos novos desenvolvimentos científicos e tecnológicos. Como condições necessárias para isso, pregaram a valorização do diálogo entre cientistas e não cientistas e a compreensão aprofundada das causas culturais e institucionais, permitindo o desenvolvimento de um espírito crítico na sociedade ${ }^{8,9}$.

Nesse contexto, para vários autores como Polino e Castelfranchi ${ }^{10}$, Castelfranchi ${ }^{11}$, Fagundes ${ }^{12,13}$, BaramTsabari e Lewenstein ${ }^{14}$ - essa mudança teve consequências diretas na figura tradicional do cientista, assim como em sua formação e em seu papel social. Além de produzir e acumular conhecimento, o cientista nesse novo cenário também começa a agir como mobilizador, empreendedor e comunicador. Esse novo cientista precisa desenvolver novas competências e passar a atuar, cada vez mais, fora dos limites de seu laboratório e instituição. Assim, promover o diálogo e ouvir os desejos dos cidadãos se torna necessário. 
O público, nesse contexto, é visto como ativo e dotado de conhecimento e opiniões legítimas, desenvolvendose, dessa forma, uma nova concepção de engajamento e participação social que reconhece a importância de se criar, ou ao menos tentar criar, canais de diálogo com o público baseados na escuta, na diversidade e no debate. Novamente, essas recomendações saíram da esfera do Reino Unido e ecoaram na Comissão Europeia, com o estabelecimento do programa e plano de ação Science and Society ${ }^{15}$, de 2002, e em diversos outros países, como no Brasil.

No Brasil, a divulgação científica existe há pelo menos dois séculos ${ }^{16}$, sendo alguns momentos emblemáticos para a área. Por exemplo, no início do século XX, a então embrionária comunidade científica brasileira lançou mão de atividades de divulgação científica para sensibilizar tomadores de decisão sobre a importância da consolidação da ciência no país, como parte das ações realizadas pela recém-criada Academia Brasileira de Ciências ${ }^{16}$. Posteriormente, em 1948, a Sociedade Brasileira para o Progresso da Ciência (SBPC) foi criada tendo a divulgação científica como um de seus eixos principais.

Agências e organizações, de caráter público ou privado, como a Financiadora de Estudos e Projetos (Finep), o Banco Nacional de Desenvolvimento Econômico e Social (BNDES) e a Fundação Vitae, contribuíram, em maior ou menor medida, em diferentes momentos, com apoio financeiro às ações de divulgação científica que foram desde o fomento e implantação de centros e museus de ciências até a formação de profissionais no campo ${ }^{16,17}$. No entanto, só mais recentemente acentuaram-se iniciativas mais sistemáticas de apoios financeiros à área da divulgação científica.

Em 2003, ano em que se iniciou um contexto político pautado na inclusão social e redução das desigualdades sociais no Brasil, aumentaram-se as iniciativas do governo brasileiro na busca por estabelecer uma política de divulgação científica, com a finalidade de diminuir a distância entre ciência e vida cotidiana, associadas à melhoria do ensino de ciências no país e ao estímulo aos jovens pelo interesse pela ciência ${ }^{18}$. Esse objetivo foi institucionalizado, principalmente, por meio da criação da Secretaria de Ciência, Tecnologia e Inclusão Social (Secis), no então Ministério de Ciência e Tecnologia (MCT). Na Secis, foi criado o Departamento de Popularização e Difusão de Ciência e Tecnologia (Depdi), ao qual foram associadas atribuições como: 1) formular políticas e implementar programas de C\&T; 2) colaborar com a melhoria do ensino de ciências, em parceria com o Ministério da Educação e com as Secretarias Estaduais de Educação; 3) apoiar centros e museus de ciências; 4) apoiar eventos de divulgação científica; 5) instituir a Semana Nacional de Ciência e Tecnologia, a partir de $2005^{19, i}$.

Segundo os dados coletados por Ferreira ${ }^{18}, 41$ editais para apoiar a divulgação científica foram lançados entre 2003 e 2012 pelo então Ministério de Ciência, Tecnologia e Inovação (MCTI), por meio do Conselho Nacional de Desenvolvimento Científico e Tecnológico (CNPq) e/ou Finep, com uma média anual de 4,1 chamadas. Entre esses 41 editais levantados, 11 contemplavam projetos de todas as áreas da popularização da ciência; a área das olimpíadas de várias áreas do conhecimento recebeu nove, sendo o segmento que recebeu o maior número de chamadas; em seguida, feiras e eventos, ambas com seis editais; áreas temáticas, como física e astronomia, com cinco; centros e museus de ciência e projetos de ciência móvel, respectivamente com três e um. Esse cenário de fomento à divulgação científica impulsionou a implementação de museus e centros de ciências e diferentes tipos de ações de divulgação científica em diversas temáticas e interface com questões sociais e as artes. A partir de 2003, houve também uma expansão de ações de alguns governos estaduais por meio das Secretarias de Ciência e Tecnologia e das Fundações de Amparo à Pesquisa (FAPs), que lançaram seus próprios editais para a divulgação científica ${ }^{16}$.

Desde 2013, entretanto, houve uma queda na média de chamadas públicas em nível nacional e estadual para a divulgação científica. No site do CNPq, Rocha ${ }^{17}$ identificou que, em 2013, foram lançados três editais,

\footnotetext{
i Palestra proferida pelo diretor do Departamento de Popularização e Difusão da CT (Depdi), Ildeu Moreira, na III Conferência Nacional de CT\&I, realizada no Rio de Janeiro, em 2005.
} 
sendo um para feiras e mostras científicas, um para a criação e desenvolvimento de Centros e Museus de Ciência e Tecnologia e outro para atividades de Difusão e Popularização da Ciência. Em 2014, apenas os editais de Feiras de Ciências e Mostras Científicas e de Olimpíadas Científicas foram lançados; em 2015, houve três editais (Feiras e Mostras Científicas; Olimpíadas Científicas; Atividades de Divulgação Científica voltadas ao Ano Internacional da Luz). Em 2016, a área contou apenas com o edital de eventos para a Semana Nacional de Ciência e Tecnologia e o de Feiras de Ciências e Mostras Científicas; em 2017, houve o edital de eventos para a Semana Nacional de Ciência e Tecnologia e o de Olimpíadas Científicas ${ }^{17}$. Em pesquisa no site do CNPq ${ }^{\text {ii }}$, encontramos que, em 2018, foram lançados três editais: Feiras de Ciências e Mostras Científicas, Olimpíadas Científicas e Apoio à Semana Nacional de Ciência e Tecnologia 2018.

Um agravante para a área foi a perda de status do Departamento de Popularização e Difusão de Ciência e Tecnologia, que, com o Decreto 8.877, de 18/10/2016, passou a ser apenas uma coordenação ${ }^{20}$. Com menos recursos financeiros e a perda de status na estrutura federal, a curva de crescimento e fortalecimento dessas ações vivenciada nos primeiros quinze anos dos anos 2000 está se invertendo, e o que se vê é a vulnerabilidade das ações de divulgação científica e do diálogo dos cientistas com a sociedade diante do atual cenário de crise econômica e política em todos os níveis de poder, tanto federal, quanto estadual e municipal. Em meados de 2017, por exemplo, não se sabia ao certo quantos dos 268 espaços científicoculturais listados pela Associação Brasileira de Museus e Centros de Ciências em 2015 ${ }^{21}$ ainda estavam abertos ao público, conforme discutem Rocha ${ }^{20}$ e Rocha e Marandino ${ }^{22}$.

Em 2018, por considerar a divulgação científica uma área estratégica para promover cada vez mais a integração das suas pesquisas, e dos cientistas com a sociedade, a Fundação Oswaldo Cruz (Fiocruz) lançou um edital para apoiar projetos de divulgação científica, com o objetivo de estimular o diálogo entre as duas partes e visando reduzir as barreiras existentes para a criação de projetos em divulgação científica.

Neste artigo, analisamos as propostas recebidas no escopo desse edital, visando dar subsídios para compreender a demanda existente e contribuir para a elaboração de uma política institucional, buscando elementos respaldados em estratégias dialógicas de divulgação científica, em modelos de comunicação pública da ciência, avaliação das estratégias e em princípios como acessibilidade e inclusão social.

\section{Universo de estudo}

A Fiocruz, vinculada ao Ministério da Saúde, possui o reconhecimento e a tradição de mais de um século trabalhando no desenvolvimento da ciência, de serviços e produtos, de informação e educação para a saúde. Ao longo de sua história, tem sistematicamente mantido um diálogo entre a comunidade científica e a sociedade, por meio de suas diferentes unidades, com ações diversas e de grande impacto. A relação da Fiocruz com a sociedade está, inclusive, prevista em seu estatuto, que estabelece como finalidade da instituição preservar, valorizar e divulgar seu patrimônio histórico, cultural e científico ${ }^{\mathrm{iii}}$. Expressão dessa faceta importante da Fiocruz é o fato de seus pesquisadores e a própria instituição terem ganhado em algumas oportunidades o Prêmio José Reis, de caráter nacional, concedido anualmente pelo CNPq.

Enquanto quase todas as unidades da Fiocruz em seus distintos campi têm em maior ou menor medida realizado ações com diferentes características de divulgação científica, um aspecto que se sobressai é a necessidade de que um número ainda maior de cientistas da instituição de diferentes níveis acadêmicos, desde estudantes e jovens cientistas a pesquisadores sêniores, e de distintas áreas do conhecimento seja sensibilizado a ter protagonismo no processo de mediação entre ciência e sociedade, incrementando seu diálogo com os cidadãos. Alguns cientistas da Fiocruz já têm se comunicado com a sociedade, ou possuem desejo de fazê-lo,

ii Disponível em: https://bit.ly/2Us9F2x. Acesso em: 08 jan. 2019.

iii O estatuto da Fiocruz está disponível em: https://bit.ly/2jHBiVk. Acesso em: 09 jan. 2019. 
mas, para que seja possível colocar ideias em prática, há uma demanda para se ter mais recursos materiais e financeiros. Outros cientistas não atuam na área, mas, se estimulados, podem ser conquistados para o campo.

Pensando em reduzir as barreiras existentes para a criação de projetos em divulgação científica, no primeiro semestre de 2018, a Vice-Presidência de Educação, Informação e Comunicação (VPEIC) da instituição, tornou público o 'Edital 2018: Propostas para Projetos de Divulgação Científica' com o objetivo de estimular o diálogo entre cientistas e sociedade ${ }^{\text {iv }}$. Dessa forma, a instituição fez uma convocatória nacional de propostas em todos os campos do conhecimento nos quais a Fiocruz atua, com prioridade para os seguintes temas: vigilância em saúde; arboviroses; resistência microbiana; violência e saúde; saúde e ambiente. Os projetos poderiam ter suas ações destinadas a atender qualquer segmento da sociedade e faixa etária. Cada projeto selecionado poderia receber um financiamento de até 20 mil reais.

A VPEIC instituiu uma comissão avaliadora, constituída de membros internos e externos à Fiocruz, para a análise dos projetos, tendo como referência os seguintes critérios, previstos no edital: Relevância do tema e de sua abordagem; Impacto social da proposta; Número de pessoas beneficiadas com a proposta; Preenchimento de importantes lacunas do conhecimento e/ou prática de divulgação científica; Beneficiamento de setores da sociedade à margem de atividades de divulgação científica; Caráter inovador da proposta; Estratégias de como o projeto e seu impacto serão avaliados; Acessibilidade.

\section{Metodologia}

Para o presente estudo, obtivemos permissão e acesso da VPEIC ao banco de todos os 145 projetos, na íntegra, submetidos ao edital. Buscando compreender a demanda expressa por meio do edital, analisamos todos os projetos submetidos, incluindo os financiados e não financiados. Esse banco de projetos foi analisado por meio de métodos mistos, uma vez que reuniu dados quantitativos e qualitativos, e que parte do material foi quantificada a partir de análise qualitativa. Como indicam Johnson e Onwuegbuzie ${ }^{23}$, o uso de métodos mistos de pesquisa possui o potencial de que palavras, imagens e narrativas possam ser usadas para dar sentido a números e, ao mesmo tempo, os números podem ser usados para dar maior precisão as palavras, imagens e narrativas. Em nosso caso, foram realizadas análises tanto qualitativas quanto quantitativas dos dados, permitindo a convergência e a corroboração das informações.

A parte qualitativa da pesquisa se deu por meio de análise de conteúdo, que visou assinalar e classificar de maneira exaustiva e objetiva as unidades de registro existentes no texto, tendo em vista os objetivos da pesquisa. Para Bardin ${ }^{24}$, esse tipo de análise se caracteriza como um conjunto de técnicas de análise das comunicações visando obter, por procedimentos, sistemáticos e objectivos de descrição do conteúdo das mensagens, indicadores (quantitativos ou não) que permitam a inferência de conhecimentos relativos às condições de produção/recepção (variáveis inferidas) destas mensagens.

Primeiramente, foram definidas as categorias a serem analisadas, tendo em vista atender os objetivos do estudo e a identificação e caracterização do perfil e as características das propostas e proponentes. Para se obter dados mais completos a respeito dos perfis dos proponentes primários (isto é, a pessoa que encaminhou a proposta), em algumas categorias identificadas a seguir, foi necessário realizar o cruzamento de informações do projeto com aquelas disponíveis publicamente no currículo Lattes.

Assim, as categorias analisadas foram:

- Distribuição geográfica da origem dos projetos submetidos;

- Unidade da Fiocruz a qual o projeto está vinculado;

- Perfil dos(das) proponentes (coautoria ou não na submissão do projeto e sexo);

iv O texto do edital está disponível em: https://bit.ly/2UMehWc. Acesso em: 09 jan. 2019. 
- A inserção dos proponentes primários na Fiocruz, que está distribuída entre as seguintes opções, conforme extraído do currículo Lattes: Pesquisadora(o); Tecnologista; Estudante de Mestrado ou Doutorado; Bolsista de Iniciação Científica; Pós-doutorando; Analista; Assessora(or); Aluna(o) de Residência; Bolsista; Celetista; Assistente; Outro4;

- Ações anteriores dos proponentes primários na área de divulgação científica, por meio do cruzamento com as informações do currículo Lattes;

- Área de pesquisa em que o projeto se insere, prioritária ou não, de acordo com o edital;

- Apresentação de estratégia de avaliação do projeto;

- Apresentação de proposta de ações ou estratégias de acessibilidade;

- Público(s) a que se destina(m) as ações e produtos de divulgação científica dos projetos;

- Formato da comunicação da ciência: se o projeto propõe/permite o diálogo entre ciência e sociedade;

- Papel do(a) cientista no projeto, ou seja, atuando como protagonista produto(s)/ ação(ões) de divulgação científica ou não;

- Produto(s)/ação(ões) de divulgação científica proposto(s) no projeto;

- Palavras mais recorrentes nos títulos e resumos dos projetos.

Após a definição dos critérios de análise, conduzimos a leitura individual e integral de todos os projetos, a fim de classificar e organizar as informações, a partir da análise de conteúdo. Os dados dessa análise foram lançados em uma planilha, possibilitando, também, a análise quantitativa e a produção de gráficos e imagens para visualização dos resultados.

Como explicitado anteriormente, em conjunto com a leitura dos projetos, foram realizadas as análises de todos os currículos Lattes dos proponentes primários, a fim de averiguar, quando não declarado no projeto, o cargo/função que exerce na Fiocruz e a presença de trabalhos anteriores em divulgação científica, no campo ‘Educação e Popularização de C\&T’ - local na plataforma em que os próprios profissionais registram projetos relacionados à área de divulgação científica. Embora o registro desse campo no Lattes não seja decisivo para mostrar todas as ações que o proponente tem desenvolvido em divulgação científica (por exemplo, há pessoas que não preenchem esta parte do currículo, mesmo com ações na área), sua análise trouxe evidências importantes para o estudo.

\section{Resultados}

\section{Distribuição geográfica dos projetos submetidos}

No total, foram inscritos 145 projetos, vindos de nove estados brasileiros, a saber: Amazonas, Bahia, Ceará, Mato Grosso do Sul, Minas Gerais, Pernambuco, Paraná, Rio de Janeiro e a unidade federativa Distrito Federal. A grande maioria, $107(73,8 \%)$ projetos, é proveniente do estado do Rio de Janeiro e há uma baixa distribuição nos outros estados: 13 projetos (9,0\%) de Pernambuco, 12 (8,3\%) de Minas Gerais, seis $(4,1 \%)$ da Bahia, dois $(1,4 \%)$ do Distrito Federal e do Mato Grosso do Sul, cada, e um $(0,7 \%)$ do Amazonas, Ceará e Paraná, cada. Esses resultados estão representados na Figura 1: 


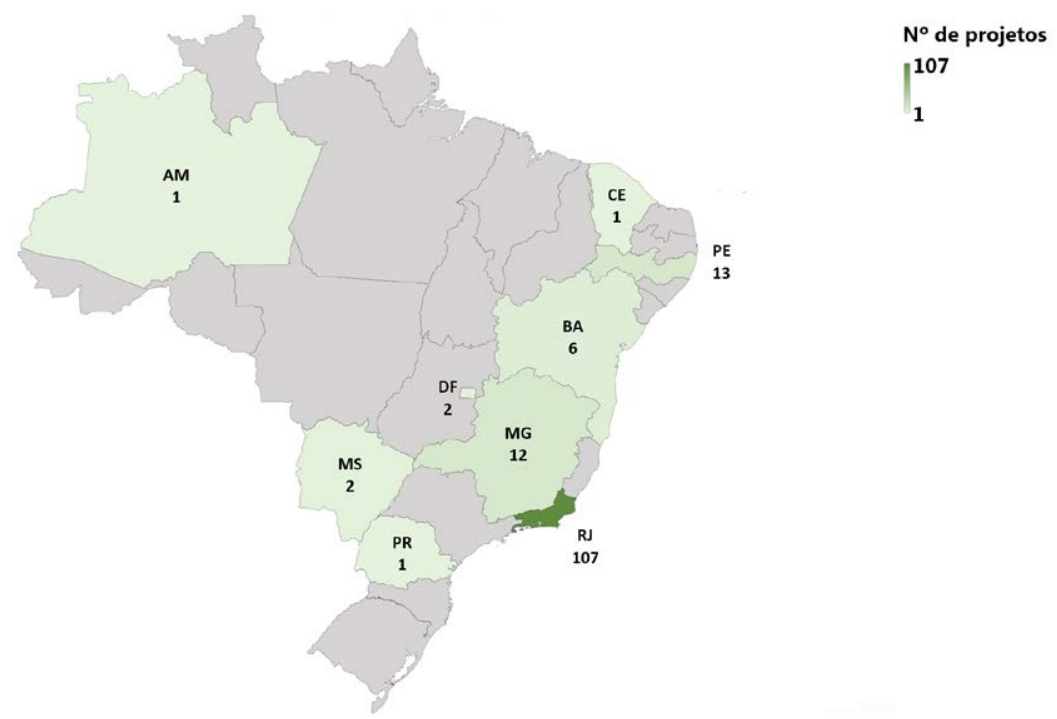

Figura 1 - Distribuição geográfica dos projetos submetidos ( $\mathrm{N}=145)$

Fonte: Os autores (2019).

\section{Distribuição dos projetos submetidos nas unidades Fiocruz}

Após a realização do estudo sobre a distribuição geográfica, averiguamos a origem dos projetos dentro da instituição Fiocruzv . A partir desta abordagem, é possível observar que 32 (21,9\%) projetos foram provenientes do Instituto Oswaldo Cruz (IOC), 25 (17,1\%) da Escola Nacional de Saúde Pública (Ensp), 13 (8,9\%) do Instituto Aggeu Magalhães (IAM), 12 (8,2\%) do Instituto René Rachou (IRR), 11 (7,5\%) do Instituto Nacional de Infectologia (INI), 10 (6,8\%) da Casa de Oswaldo Cruz (COC), sendo oito (5,5\%) do Museu da Vida. Ademais, seis $(4,1 \%)$ são originários do Instituto Gonçalo Moniz (IGM), cinco $(3,4 \%)$ da Escola Politécnica de Saúde Joaquim Venâncio (EPSJV) e Instituto de Comunicação e Informação Científica e Tecnológica (Icict) cada, três (2,1\%) do Instituto Fernandes Figueira (IFF) e da Gerência Regional de Brasília (Fiocruz-DF), cada, dois (1,4\%) do Escritório Regional de Mato Grosso do Sul (Fiocruz-MS), Instituto Nacional de Controle da Qualidade em Saúde (INCQS) e Farmanguinhos cada e, por fim, um (0,7\%) projeto do Instituto Leônidas e Maria Deanne (ILMD), do Instituto Carlos Chagas (ICC), do Escritório Regional de Ceará (Fiocruz-CE), da Creche Fiocruz, da Vice-Presidência de Ambiente, Atenção e Promoção da Saúde (VPAAPS) e do Instituto de Ciência e Tecnologia em Biomodelos (ICTB), cada. Outros nove $(6,2 \%)$ projetos vieram da Presidência, dos quais três $(2,1 \%)$ foram provenientes da Editora, dois (1,4\%) do Programa de Desenvolvimento do Campus Fiocruz da Mata Atlântica, dois (1,4\%) da IdeiaSUS, um (0,7\%) do Centro de Estudos Estratégicos (CEE) e um (o,7\%) do Centro de Desenvolvimento Tecnológico em Saúde (CDTS). Notamos que o somatório total (146) é superior ao número total de projetos (145), pois um dos projetos foi submetido em ação conjunta de duas unidades - IOC e Ensp. Este resultado está representado na Figura 2, a seguir.

v É possível acessar o organograma da Fiocruz em: https://portal.fiocruz.br/organograma. Acesso em: 27 jul. 2018. 


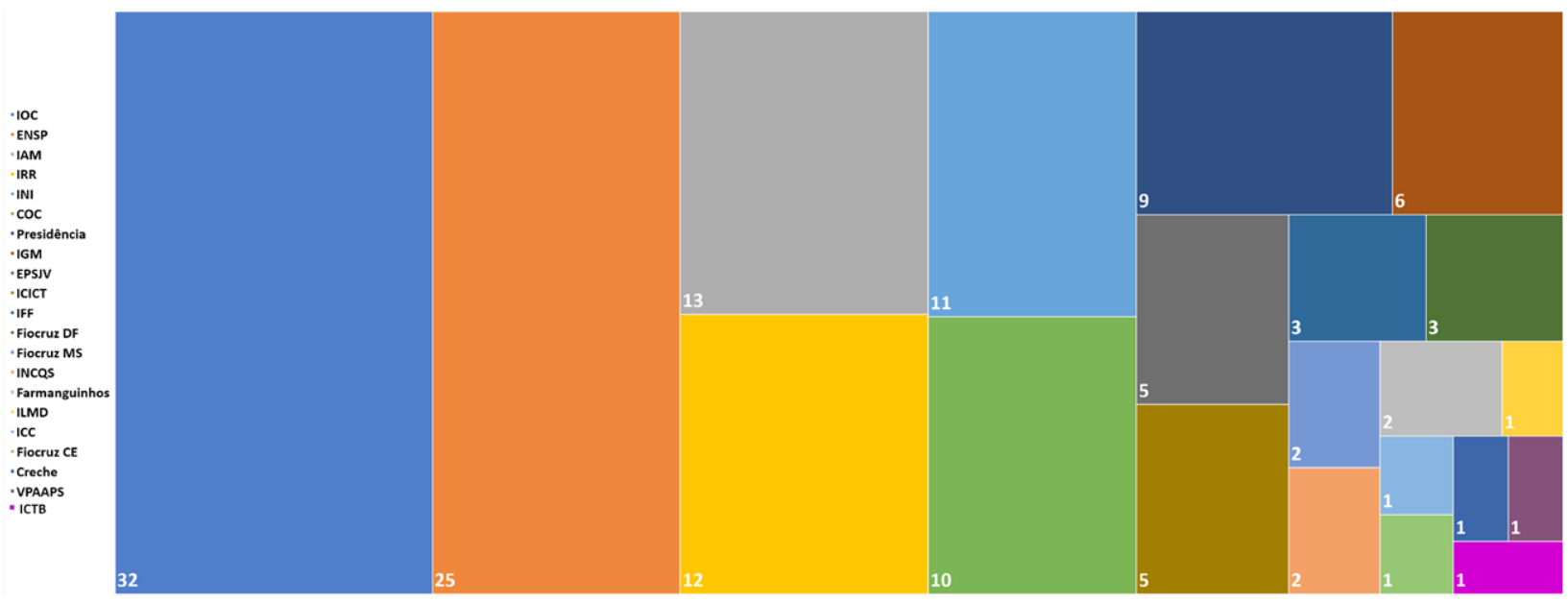

Figura 2 - Distribuição dos projetos de acordo com a unidade Fiocruz $(\mathrm{N}=146 *)$

* um projeto foi proposto conjuntamente por duas unidades

Fonte: Os autores (2019).

\section{Perfil dos(as) proponentes}

Dos 145 projetos submetidos ao edital, a maioria, 102 (70,3\%) foi aplicada em nome de apenas um(a) proponente. Nove $(6,2 \%)$ projetos contavam com dois proponentes, oito $(5,5 \%)$ contavam com seis proponentes e cinco $(3,4 \%)$ projetos com três ou quatro proponentes. O projeto que teve o maior número de proponentes tinha 16 nomes inscritos, como pode ser observado na Figura 3. No total, 354 pessoas estiveram envolvidas nas propostas apresentadas.

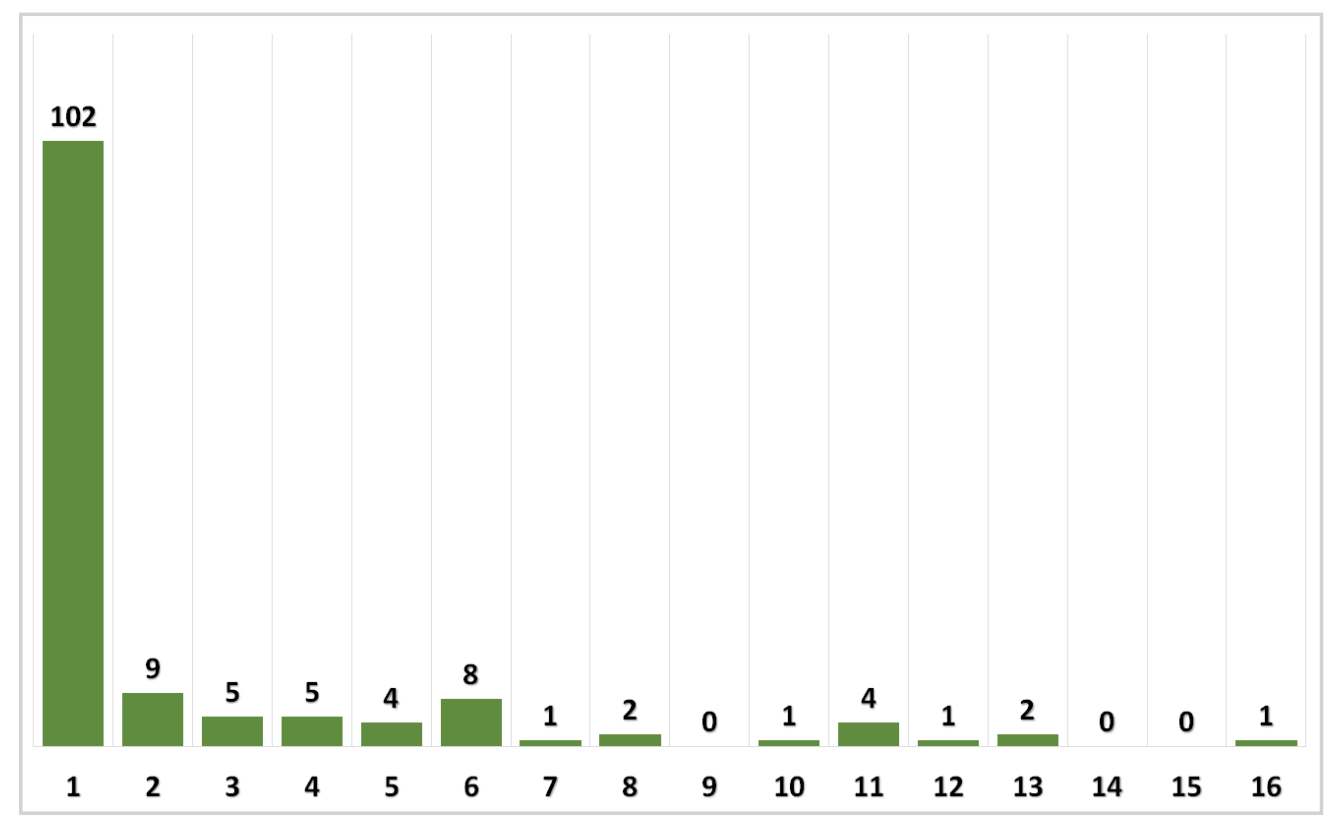

Figura 3 - Número de proponentes por projeto $(\mathrm{N}=145)$

Fonte: Os autores (2019).

Ao se analisar o sexo dos(as) proponentes primários(as), observamos uma presença maior de mulheres, com 63\% de participação (92), enquanto o sexo masculino teve a participação de 37\% (53), como ilustrado pela Figura 4. 


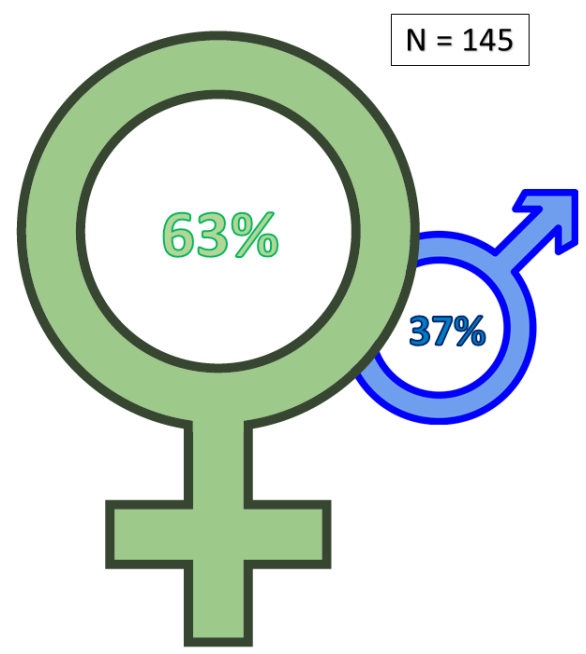

Figura 4 - Distribuição de sexo dos proponentes primários Fonte: Os autores (2019).

Em relação ao vínculo que os proponentes primários possuem com a Fiocruz - tendo como fonte o currículo Lattes, como explicamos anteriormente -, percebe-se que 65 proponentes, que correspondem a (45\%) dos 145 projetos, são pesquisadores, seguidos por 39 tecnologistas (27\%) e 16 estudantes de mestrado e doutorado (11\%). Proponentes que não possuem ou não tiveram seus currículos Lattes identificados, ou ainda, que não indicaram seu vínculo com a Fiocruz no projeto foram alocados na opção ‘outro', totalizando 2\% (3). A Figura 5 mostra a distribuição:
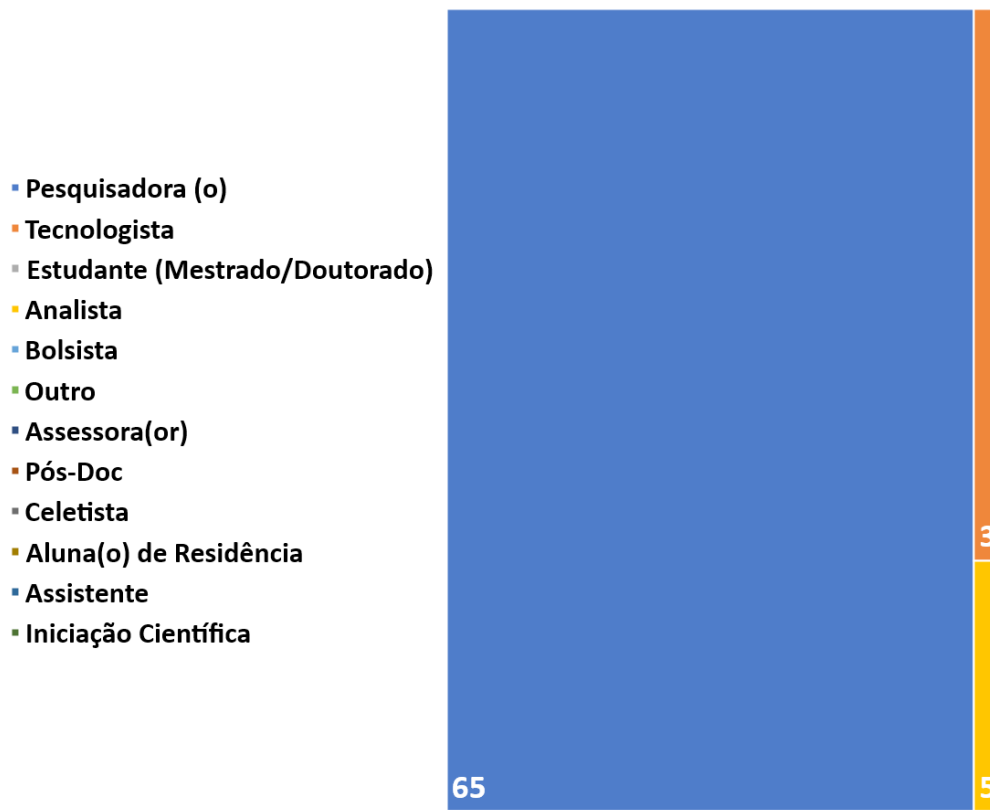



Figura 5 - Número de proponentes primários distribuídos por vínculo com a Fiocruz ( $\mathrm{N}=145)$ Fonte: Os autores (2019).

Ao avaliar o currículo cadastrado na plataforma Lattes dos autores primários dos projetos, identificamos que 61\% (88 de 145) autodeclararam já ter realizado algum tipo de ação/projeto que se encaixa na aba 'Educação e Popularização de C\&T', destinada a projetos e ações de divulgação científica. Do total, 54 proponentes primários (37\%) não declararam ações desta natureza em seus currículos, e três proponentes (2\%) não possuíam ou não tiveram encontrados seus respectivos currículos Lattes. 


\section{Perfil dos projetos}

$\mathrm{Na}$ análise dos projetos submetidos, em uma primeira fase, tomamos como base alguns critérios de julgamento presentes no edital, tais como: (a) se os projetos submetidos se enquadravam ou não nas áreas prioritárias definidas pelo edital; e (b) se apresentavam propostas de avaliação e estratégias de acessibilidade.

Assim, a partir da análise de conteúdo dos projetos, foi realizada a identificação a fim de apurar se os projetos submetidos se enquadravam nas áreas prioritárias - vigilância em saúde, arboviroses, resistência microbiana, violência e saúde e saúde e ambiente. Para aqueles que não se enquadravam nessas áreas, buscamos identificar a quais áreas de conhecimento estavam ligados.

Entre os 145 projetos submetidos, alguns realizavam ações em mais de uma área, sendo encontrado, portanto, um número total de 165 ocorrências $(\mathrm{N}=165)$. Entre essas, 83 projetos $(50 \%)$ estavam entre as áreas consideradas prioritárias no edital, sendo que 28 (17\%) tratavam sobre o tema saúde e ambiente; 23 (14\%), arboviroses; 18 (11\%), vigilância em saúde; 12 (7\%), violência e saúde; e dois (1\%), resistência microbiana. Cerca de metade das propostas estavam atreladas a outras áreas além das que foram consideradas prioritárias pela instituição (82 de 165). Dentro do espectro dos temas dos projetos podemos destacar a presença, por exemplo, de doenças negligenciadas e emergentes, doenças hepáticas crônicas e sexualmente transmissíveis, células-tronco, saúde dos povos indígenas, obesidade, saúde mental, ciência e arte, mulheres em risco, economia solidária, câncer, bullying, infecções fúngicas humanas, diabetes, acessibilidade e inclusão.

Outro critério de julgamento presente no edital foi a previsão de avaliação do projeto. O resultado da análise mostra que apenas 58 (40\%) dos projetos submetidos previam alguma ação/estratégia de avaliação, enquanto 87 (60\%) não mencionaram ações com esse fim.

Diante da constante demanda de se atingir diversos tipos de públicos e dos atuais esforços da instituição para a consolidação de uma política de acessibilidade e inclusão, especialmente a partir da criação do Comitê Fiocruz para Acessibilidade e Inclusão das Pessoas com Deficiências, um dos critérios do edital foi a proposição de estratégias de acessibilidade. Apesar disso, apenas 10 (7\%) projetos aplicados mencionaram a realização de algum tipo de ação ou proposta de acessibilidade, sendo elas, por exemplo, a contratação de uma equipe de intérpretes de Libras para a tradução de eventos, oficinas, seminários, vídeos e jogos, implementações e considerações de estrutura na construção de websites, cartilhas e folhetos acessíveis em Braille e algumas adaptações físicas de infraestrutura.

Para além desses critérios de julgamento já previstos no edital, realizamos, em um segundo momento, a análise dos projetos sob a ótica de outras categorias, a fim de atender os objetivos do presente estudo. Executando um levantamento do público a que se destinavam os projetos submetidos, identificamos que grande parte deles propunha atendê-lo de uma forma geral - ou seja, sem especificar estratos sociais, faixas etárias ou grupos específicos - com 57 recorrências (29\%). O foco em grupos de 'estudantes' ocorreu com a segunda maior frequência, tendo 46 ocorrências (23\%). Outros 37 projetos (19\%) indicavam suas ações para um público específico, por exemplo, moradores de uma determinada região, pacientes de uma determinada enfermidade ou, ainda, determinadas profissões, como professores. Além do público específico, houve 32 ocorrências (16\%) de projetos focados em especialistas em determinada área do conhecimento, principalmente aquelas voltadas para a área de saúde. Por fim, 25 projetos (13\%) tiveram a intenção de atender agentes de saúde. No total, foram 197 ocorrências entre 145 projetos, visto que vários projetos tinham mais de uma audiência explicitada. O detalhamento desses resultados pode ser observado na Figura 6 que segue: 


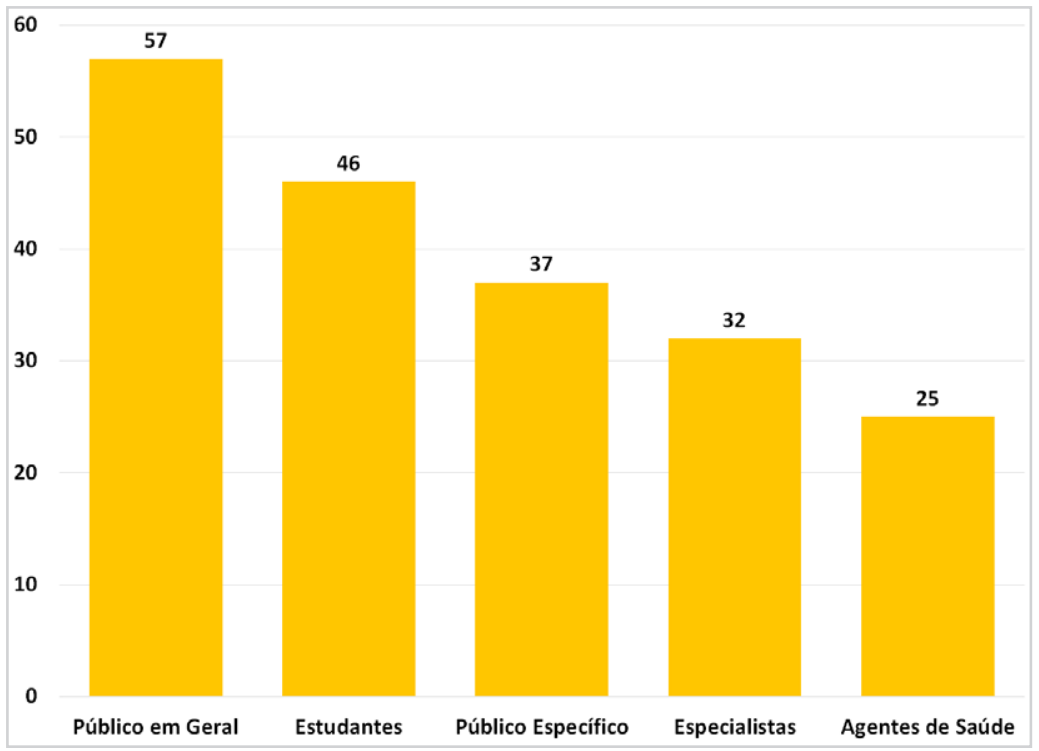

Figura 6 - Público a quem se destinam os projetos $(\mathrm{N}=197)$ Fonte: Os autores (2019).

Do ponto de vista da divulgação científica, um aspecto considerado relevante é a análise sobre se o projeto, de alguma forma, explicita o potencial para promover o diálogo entre cientistas e a sociedade. Para tal, baseados em referenciais teóricos da área, tal como Brossard e Lewenstein ${ }^{25}$, entendemos que há uma proposta de 'diálogo' entre cientistas e sociedade quando diferentes grupos da sociedade - exceto especialistas da área do conhecimento que se pretende divulgar -, podem interagir/comunicar de alguma forma com os cientistas/especialistas dessa área, mesmo que não seja em tempo real e de forma presencial, mas, por exemplo, virtualmente. Isso permite que diferentes estratos da sociedade tenham o direito de pergunta e resposta, de questionamento, e que, assim, possam se posicionar de alguma forma diante do conhecimento divulgado.

Tendo em vista essas definições, a análise dos projetos mostrou que aproximadamente a metade, 74 (51\%), explicitam esse tipo de interação dialógica entre cientistas/especialistas e sociedade: seja por meio de oficinas, palestras ou websites e plataformas online. Outros $71(49 \%)$ projetos não apresentavam a possibilidade explícita de interação e comunicação por parte da sociedade, como por meio da produção e construção de websites ou podcasts que não previam a troca, compartilhamento de ideias e/ou questionamentos por parte da sociedade, a distribuição de materiais impressos, ou ainda, seminários explicitamente direcionados para a comunidade científica ou público bastante especializado na temática a ser divulgada.

No que se refere ao papel do cientista no projeto, consideramos que o proponente pode ter seu papel considerado 'protagonista' quando está diretamente envolvido na realização do produto/ação de divulgação científica proposto. Por meio dessa interpretação, observamos que 100 (69\%) dos proponentes possuíam papel ativo na elaboração e desenvolvimento do(s) produto(s) dos projetos e 45 (31\%) não estavam envolvidos na proposta com o papel de protagonista.

Entre os 145 projetos submetidos, foi possível encontrar diversas formas e produtos de divulgação científica, sendo alguns recorrentes. Para essa categorização, realizamos a identificação dos termos que se relacionavam com as propostas de produtos/ações e conduzimos a análise de conteúdo, totalizando 721 palavras nos 145 projetos. Em seguida, foi elaborada uma imagem no estilo 'nuvem de palavras' para 
ilustrar, por meio de uma escala de tamanho, os termos mais recorrentes. Excluímos termos de ligação e somamos em uma mesma contagem termos no singular e plural ('material' e 'materiais', por exemplo ${ }^{\text {vi). }}$

Dessa maneira, obtivemos a maior ocorrência dos termos: realização de oficinas (33 recorrências em 721 palavras), materiais de divulgação e informativos (25), websites (21), vídeos (19), difusão (de maneira ampla) (17), eventos ou palestras (13), informativos (11), cursos (10), entre outras, como seis propostas de ebooks, cinco propostas de criação de podcasts e nove ações em escolas, conforme ilustrado na Figura 7.

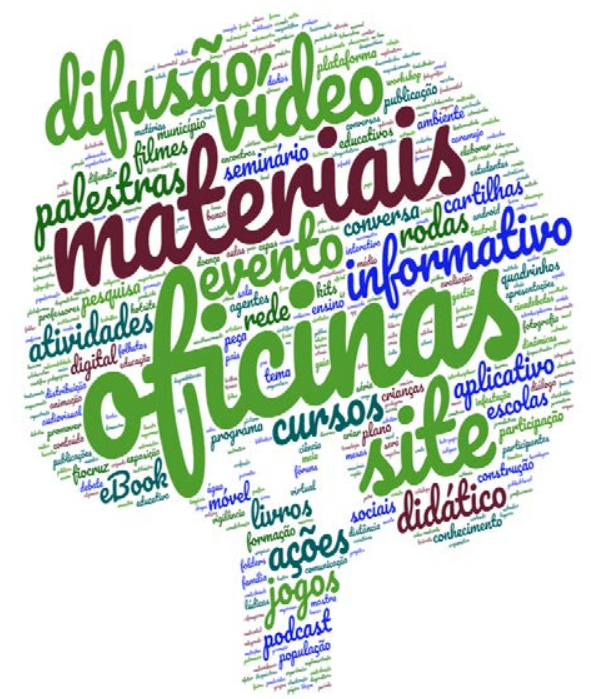

Figura 7 - Árvore dos produtos e ações de divulgação científica propostos nos projetos Fonte: Os autores (2019).

Utilizando a mesma metodologia e forma de representação, analisamos os títulos e resumos dos 145 projetos. A partir do conteúdo dos títulos, dos quais obtivemos um total de 1.271 palavras, observamos que as palavras mais frequentes foram: 'saúde', com 65 ocorrências, seguida por termos vinculados intrinsecamente ao edital, como 'divulgação' (32 ocorrências), 'científica' (25), 'ciência' (18), 'educação' (16) e 'doenças' (15) (ver Figura 8). Esses dados refletem que a temática da saúde prevalece como principal nas propostas de divulgação científica, e que temáticas, direta e indiretamente relacionadas com o termo, como doenças, arboviroses, vetores e prevenção se fizeram presentes. Além disso, é possível observar que temas paralelos como educação, ciência, estratégias, sociedade e desenvolvimento também foram bastante frequentes, o que pode evidenciar uma correlação entre os temas de saúde sendo divulgados por meio da educação, levando-se em conta a sociedade e diversas estratégias para alcançá-la.

vi Entendemos como 'materiais' toda a produção de material físico para a divulgação científica, como folhetos, cartazes e livros, por exemplo. 




Figura 8 - Ocorrências de palavras nos títulos dos projetos Fonte: Os autores (2019).

Analisando, de forma semelhante, o conteúdo dos resumos dos projetos submetidos, observamos novamente o domínio do termo 'saúde': 463 citações em um total de 15.199 ocorrências divididas em 2.385 diferentes termos. O segundo e terceiro termos mais citados nos resumos também são 'divulgação' (141) e 'científica' (140), seguidos por 'informações' (120), 'sociais' (98), 'conhecimento' (95), 'educação' (85), 'pesquisa' (83), 'população' (82), 'Fiocruz' (82), 'doenças' (81) e ‘sociedade' (75), como pode ser visto na representação na Figura 9, a seguir.

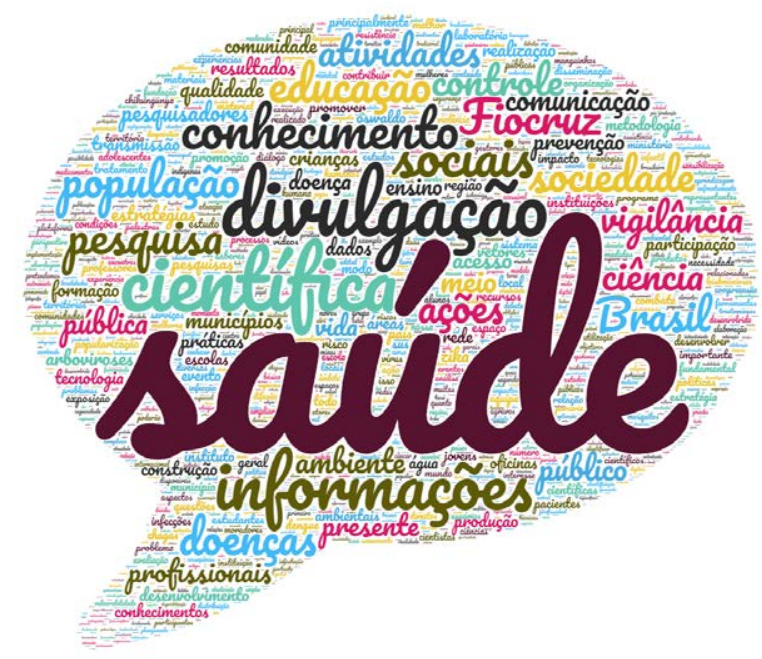

Figura 9 - Ocorrências de palavras nos resumos dos projetos Fonte: Os autores (2019).

\section{Discussões e considerações finais}

Dos 145 projetos submetidos, 13 projetos foram contemplados com o financiamento da Fiocruz, oriundos das seguintes localidades: seis do estado do Rio de Janeiro, quatro de Pernambuco, dois de Minas Gerais e um do Mato Grosso do Sul. Dessa forma, três regiões brasileiras foram contempladas no edital: Sudeste, Centro-Oeste e Nordeste. Entre os projetos aprovados, quatro foram do IAM, dois IOC e IRR, cada, e um da Ensp, COC, Presidência (Fiocruz da Mata Atlântica), Icict e Fiocruz MS, cada. 
Um primeiro aspecto que surgiu da análise deste edital é que existe uma clara demanda na instituição por apoio a projetos de divulgação científica. Expressão disso foi o fato de que 21 setores da instituição, entre unidades e projetos especiais da Presidência, submeteram propostas ao edital. Também observamos que, apesar de grande parte dos projetos submetidos serem do Rio de Janeiro (73,8\% das propostas), houve uma mobilização importante dos distintos campi da Fiocruz, com a participação de nove diferentes unidades na extensão nacional. O próprio número total de proponentes (primários e coautores), 354, também expressa tal interesse.

Identificamos que a grande maioria dos projetos submetidos (102) teve somente um único propositor. Sem criticar aqueles que preferem propor projetos individuais - e também levando em conta que o montante máximo para cada projeto era de 20 mil reais - é importante lembrar que a diversidade de atores sociais, formações e expertises é um aspecto relevante na divulgação científica. Isso sinaliza que pode ser desejável o estímulo à promoção de colaborações no desenvolvimento dos projetos, podendo, por exemplo, em editais futuros, incluir uma faixa de valor superior de apoio para projetos que contemplem colaborações e aspectos de cocriação ${ }^{26}$.

Os dados revelam, também, que um percentual maior de proponentes é do sexo feminino - 92 ocorrências (63\%). Para Abighannam²7, a presença feminina na área da divulgação científica ainda não poder ser definida de forma precisa, assim como, Johnson, Ecklund e Lincoln ${ }^{28}$ sugerem que há inúmeros fatores subjetivos e entrelinhas que determinam as experiências de mulheres e homens na divulgação científica e que isso não é facilmente captável por pesquisas quantitativas. Delicado ${ }^{29}$, por sua vez, destaca que a presença feminina na área científica é uma questão de pesquisa que tem sido bastante abordada na literatura, assim como em programas de aferição, em estatísticas e em políticas públicas. Menos atenção tem sido dada, contudo, para a questão específica das mulheres na divulgação científica, apesar da sua importância crescente. Ainda segundo Delicado ${ }^{29}$, o número de divulgadoras científicas não pode ser visto de forma isolada à inserção das mulheres na ciência e nas carreiras científicas (e também no mercado de trabalho), uma vez que todas essas relações são entrelaçadas. A partir dessa abordagem, a autora afirma que, apesar de poucos estudos sobre o perfil dos profissionais da divulgação da ciência, os mais atuais apresentam evidências que demonstram o protagonismo feminino na área - por exemplo, na França, em 2011, Jensen ${ }^{30}$ já apresentava resultados de que mulheres cientistas estavam mais envolvidas que homens na divulgação científica. Para outros autores, como De Welde e Laursen ${ }^{31}$; Johnson, Ecklund e Lincoln ${ }^{28}$ e Andrews, Weaver, Hanley, Shamatha e Melton ${ }^{32}$, as mulheres estão encontrando novas oportunidades de liderar a divulgação científica, de se conectar diretamente com seus públicos. Além disso, a visibilidade feminina nessa área é, de fato, importante porque pode potencializar a promoção do interesse e do engajamento de outras mulheres e meninas na ciência. Na Fiocruz, houve um equilíbrio entre homens e mulheres contemplados dentre os 13 projetos aprovados no edital, sem prevalecer, contudo, a figura feminina, sendo sete do sexo masculino e seis do feminino.

Um aspecto importante é o fato de que há uma gama diversificada de proponentes, de pesquisadores e outros profissionais, de sêniores a jovens, incluindo estudantes até mesmo de iniciação científica. Essa diversidade também se refletiu nos projetos aprovados, em que há quatro pesquisadores, quatro tecnologistas, dois estudantes de mestrado ou doutorado, um analista, um estudante de iniciação científica e um celetista.

Diagnosticamos, ainda com relação ao perfil dos proponentes primários, que 61\% (88) haviam realizado algum trabalho anterior em 'Educação e Popularização da Ciência e Tecnologia', conforme explicitado em seus respectivos currículos Lattes. A distribuição entre a presença e a ausência de ações nessa aba do Lattes entre os 13 projetos aprovados se manteve aproximadamente a mesma de todos os projetos submetidos: oito dos 13 (62\%) proponentes primários dos projetos aprovados declararam haver realizado ações anteriores e cinco (38\%) declararam não as haver realizado. Isso sinaliza que, por um lado, pessoas que já têm atuado na divulgação científica submeteram projetos - o que, obviamente, é importante -, mas também evidencia que pessoas não anteriormente 'fisgadas' pela divulgação científica dedicaram seu tempo para consolidar um projeto nessa área, o que consideramos uma contribuição do edital. 
Como vimos, apesar de o edital ter sido aberto para a submissão de projetos de quaisquer áreas, a VPEIC da Fiocruz definiu cinco temas como sendo prioritários para a instituição: saúde e ambiente, arboviroses, vigilância em saúde, violência e saúde e resistência microbiana. Muitos projetos trabalharam em múltiplas áreas, fazendo com que o número total de ocorrências (165) fosse superior ao número total de projetos (145). Entre os projetos que pertenciam ao espectro das áreas prioritárias, podemos salientar a presença baixa de projetos com o foco em resistência microbiana: apenas dois projetos. Dentre os demais temas prioritários, houve uma distribuição equilibrada com 28 em saúde e ambiente, 23 em arboviroses, 18 em vigilância da saúde e 12 em violência e saúde. Cerca de metade das propostas estavam atreladas a outras áreas além das que foram consideradas prioritárias pela instituição (82 de 165), evidenciando que há outras áreas consideradas importantes pelos trabalhadores da Fiocruz, que também podem ser consideradas em um próximo edital.

Interessou-nos entender também como os projetos abordaram e propuseram seus produtos e ações de divulgação científica. Para tal, nos apoiamos em literatura especializada, com destaque para Brossard e Lewenstein ${ }^{25}$ que definem dois tipos gerais de projetos na área de divulgação científica (que podem se sobrepor): a) projetos que almejam melhorar os níveis de entendimento dos públicos em uma área específica da ciência; e b) projetos que visam favorecer a interação dos públicos e dos cientistas. Segundo os autores, nos últimos anos foram realizados alguns esforços para se integrar essas duas categorias, ligando os resultados de pesquisas com atividades de divulgação científica.

O que vemos no contexto dos projetos submetidos ao edital da Fiocruz é que os produtos propostos nas ações de divulgação científica ainda estão muito baseados no primeiro tipo - aqueles que almejam melhorar os níveis de entendimento dos públicos em uma área específica da ciência. Como vimos na análise dos dados, a realização de oficinas foi a atividade mais recorrente, seguida pela confecção de materiais de divulgação e informativos, desenvolvimentos de websites e criação de vídeos. Esses dados sugerem que a divulgação científica pelo olhar das pessoas que propuseram projetos pode estar mais centrada em um modelo de alfabetização científica e de ensino-aprendizagem, ou seja, propostas que seguem modos de divulgar a ciência ainda atrelados à educação formal e modelos pedagógicos. Sem reduzir a importância dessa modalidade de iniciativas, destacamos a necessidade de estimular mais ações que permitam outros e variados tipos e modos de interação, articulação, diálogo e coconstrução entre os públicos e a comunidade científica.

Apesar de a maior parte dos projetos submetidos ao edital não especificar um foco quanto ao público-alvo, 57 dos 197 (29\%) tinham a intenção de atender qualquer setor da sociedade. Os projetos que detalharam o público a que eram destinados tinham como o principal foco estudantes: 46 ocorrências, representando $23 \%$ do total. Novamente, destacamos que não há dúvida da importância de realizar ações de divulgação científica para estudantes, no entanto, como apontam Patiño e colaboradores ${ }^{33}$, outros setores da sociedade estão subatendidos por ações de divulgação científica, especialmente, no âmbito da região da América Latina. Por isso, de modo similar à indicação anterior, ressaltamos a necessidade de se pensar públicos que ainda não estão sendo contemplados com ações de divulgação científica pelas instituições e profissionais brasileiros.

Analisando especificamente a existência de diálogo entre cientistas e sociedade - objetivo explícito do edital - nos projetos submetidos, observamos que aproximadamente a metade deles não apresentaram ações neste sentido. Este fato reforça novamente a argumentação anterior fundamentada em Brossard e Lewenstein ${ }^{25}$ de que os projetos almejam melhorar os níveis de entendimento dos públicos e ensiná-los sobre uma área específica da ciência, mas o modelo de déficit na divulgação científica ainda prevalece. Esse dado reitera, ainda, a afirmação de Moreira e Massarani ${ }^{34}$ e Massarani ${ }^{35}$ de que, no contexto nacional, continua existindo a 'hegemonia' do modelo de déficit de conhecimento e da alfabetização científica, em que a divulgação científica ainda é muito centrada na apresentação de conteúdos e fenômenos científicos que, conforme mencionamos antes, também é importante, mas as ações de divulgação científica não devem se ater somente a esse formato e modelo. 
Com pequenas nuances, pesquisadores estrangeiros como Trench ${ }^{36}$, Bauer, Allum e Miller ${ }^{6}$ e Wynne ${ }^{37}$ expressam que, em muitos casos, a mudança das ações de divulgação científica baseadas no modelo de déficit para o diálogo foi mais nominal do que efetiva. Essa questão está tão forte entre os debates acadêmicos que uma das mais importantes revistas da área, a Public Understanding of Science, publicou, em 2016, um volume inteiro visando debater "Por que a ideia de déficit sempre retorna?"38. Para que o processo de participação pública ocorra com maior eficácia, Bandelli39 propõe a criação de novos métodos e plataformas de engajamento. Além disso, sugere a necessidade de se implementar novas pesquisas que busquem entender o papel da divulgação científica em distintas instituições para o envolvimento da sociedade com a ciência, por exemplo, estudos sobre a relevância da cidadania científica em níveis municipais e regionais e a continuidade de práticas inclusivas e de engajamento do público, como práticas de ciência-cidadã. Contudo, como também aponta Pohlman ${ }^{40}$, apesar de distintas instituições estarem decididas a facilitar a discussão entre cientistas e seus públicos, elas enfrentam obstáculos ao transformar a ideia de diálogo em programas viáveis e eficazes. Interações face a face entre os pesquisadores e o público acarretam dificuldades, como custo e disponibilidade de agenda, mas é ainda maior o desafio desses programas de moldar as expectativas dos cientistas e não-cientistas a um ponto em que o diálogo se torne possível. Os dados analisados no presente estudo nos indicam que tais desafios também podem estar afetando a comunidade da Fiocruz, manifestando uma demanda latente por mais informações e aprofundamento na área da divulgação da ciência, o que pode ser suprido, por exemplo, com cursos de curta duração e/ou pós-graduações, bem como eventos científicos, seminários e, sem dúvida, o contínuo estímulo e financiamento a projetos de divulgação científica, como foi realizado em 2018.

Por fim, chamou a atenção que a maioria dos projetos submetidos não possuíam propostas de ações de acessibilidade ou estratégias de avaliação, ambos critérios explicitamente apontados no edital.

Apenas dez entre 145 projetos propostos apresentaram algum tipo de proposta de estratégia para a promoção da acessibilidade e inclusão. Dos dez que possuíam algum tipo de ação de acessibilidade, três foram aprovados (entre 13), gerando um aumento na proporção de acessibilidade entre os projetos aprovados, mas ainda muito distante de valores que podemos considerar adequados. Entre as estratégias de acessibilidade propostas pelos projetos aprovados, identificamos: tradução de português para Libras, fontes aumentadas e experimentos táteis, além da exigência de salas que cumpram as regras de acessibilidade. No entanto, vale ressaltar que a partir da formulação apresentada nos distintos projetos submetidos, conseguimos extrair evidências de que os conceitos de acessibilidade não estão devidamente incorporados em muitos dos proponentes. Isso sugere que, a despeito do fato de que acessibilidade é área prioritária na Fiocruz, muitos trabalhadores da instituição não estão familiarizados com as discussões existentes, sinalizando para a importância de uma maior sensibilização sobre o tema. Sabemos que, de fato, promover a acessibilidade e a inclusão em ações de divulgação científica ainda é desafiador e que as instituições ainda estão em um processo de implementação dessas ações, como pode ser visto em publicações recentes, como em Rocha et $a l .{ }^{41}$ e Rocha et $a l . .^{42}$. É de nosso conhecimento que a Fiocruz está promovendo uma política de inclusão e, a partir disso, acreditamos que há uma grande chance de que, em editais futuros, essa demanda seja mais e melhor contemplada pelos proponentes.

Com relação à avaliação, observamos que os dados mostram que 58 (40\%) projetos apresentaram alguma proposta, enquanto 87 (60\%) não sugeriram qualquer ação de avaliação; entre os projetos que foram aprovados, oito dos 13 (61\%) sugeriram algum tipo de ação. A presença reduzida de iniciativas de avaliação, na verdade, é um desafio em nível latino-americano, como apontam Patiño e colaboradores ${ }^{33}$. Esses dados endossam o que alguns pesquisadores na área de divulgação científica, como Bucchi e Trench ${ }^{43}$ e Marandino et al. ${ }^{44}$ já vêm discutindo: ainda há uma necessidade de se criar estratégias e institucionalizar a avaliação das ações e políticas de divulgação científica. Para Bucchi e Trench43, "A comunicação pública da ciência deveria estar [...] suficientemente amadurecida para [...] uma fase em que critérios de qualidade são centrais 
para todas as partes envolvidas. Isso implica desenvolver indicadores e parâmetros de performance, particularmente para instituições, e destinar importância à questão da avaliação". Bandelli39 também explicita que há um crescente interesse na avaliação dos resultados provenientes das diferentes atividades para a participação do público. Desse modo, propor meios de avaliar de forma criteriosa a divulgação da ciência, bem como os processos e resultados dos projetos financiados, é relevante e necessário para uma política na área na Fiocruz.

Para finalizar, ressaltamos que, em 2017, a Comissão Europeia lançou seu novo plano de trabalho para 2018-2020 intitulado Science with and for Society, em que renova sua demanda de envolver a população como atores diretos na produção e difusão do conhecimento sobre ciência, tecnologia e inovação45. Em linhas gerais, o documento aponta metas para acelerar e catalisar processos de transformação institucionais sugerindo estratégias como a colaboração com a educação científica, métodos inovadores de ensinar ética e integridade na pesquisa, a reutilização de dados de pesquisas financiados com recursos públicos e a ciência para os refugiados. Somado a isso, orientam estratégias voltadas para a igualdade de gênero na pesquisa e política de inovação, a construção de redes e parcerias entre diversos tipos de instituições e a exploração e suporte à 'ciência-cidadã'.

O documento demonstra que, em nível internacional, o desafio se renova para os próximos anos. Na perspectiva brasileira, como Massarani e Moreira ${ }^{16}$ apontam, ainda há uma trajetória a ser percorrida, com uma demanda de políticas públicas, de financiamento e de ação coletiva de profissionais e instituições envolvidos com o trabalho científico e sua comunicação. Nesse contexto, recomendamos que a chamada pública feita pela Fiocruz em 2018 para apoiar projetos de divulgação científica seja realizada anualmente, associada ao desenvolvimento de programas e ações de capacitação dos cientistas e da comunidade científica para estabelecer o diálogo com a sociedade, de forma diversificada, abrangente, acessível e inclusiva.

\section{Referências}

1. Royal Society. The public understanding of science. London: The Royal Society; 1985.

2. Miller S. Os cientistas e a compreensão pública da ciência. In: Terra incógnita: a interface entre ciência e público. Rio de Janeiro: Casa da Ciência/UFRJ, Museu da Vida/Fiocruz, Vieira \& Lent; 2005. p. 115-32.

3. Bodmer W. Public understanding of science: the BA, the Royal Society and COPUS. Notes Rec R Soc [Internet]. 2010 Sept 20 [cited 2018 Nov 10];64(Suppl_1):S151-S161. Available from: https:// royalsocietypublishing.org/doi/full/10.1098/rsnr.2010.0035. doi: https://doi.org/10.1098/rsnr.2010.0035

4. Castelfranchi Y. Para além da tradução: o jornalismo científico crítico na teoria e na prática. Santa Cruz de la Sierra: Jornadas Iberoamericanas sobre la ciencia en los medios masivos; 2008.

5. Lewenstein BV. Editorial: a decade of public understanding. Public Underst Sci [Internet]. 2002 Jan 21 [cited 2018 Nov 10];11(1):1-4. Available from: https://bit.ly/2ZsVB]J. doi: https://doi.org/10.1088/0963$6625 / 11 / 1 / 001$

6. Bauer MW, Allum N, Miller S. What can we learn from 25 years of PUS survey research? Liberating and expanding the agenda. Public Underst Sci [Internet]. 2007 Jan 18 [cited 2018 Nov 10];16(1):79-95. Available from: http://journals.sagepub.com/doi/10.1177/0963662506071287.

7. House of Lords. Science and technology: third report. London: Her Majesty's Stationery Office; 2000.

8. Miller S. Public understanding of science at the crossroads. Public Underst Sci. 2001;10(1):115-20. doi: https://doi.org/10.3109/a036859

9. Hamlett PW. Technology theory and deliberative democracy. Sci Technol Hum Values [Internet]. 2003 Jan 18 [cited 2018 Nov 10];28(1):112-40. Available from: https://bit.ly/2KRU6BD. doi: https://doi. org/10.1177/0162243902238498

10. Polino C, Castelfranchi Y. The communicative turn in contemporary techno-science: Latin America approaches and global tendencies. In: Science communication in the world: practices, theories and trends. New York: Springer; 2012. p. 3-17. 
11. Castelfranchi Y. Por que comunicar temas de ciência e tecnologia ao público? (Muitas respostas óbvias... mais uma necessária). In: Jornalismo e ciência: uma perspectiva ibero-americana. Rio de Janeiro: Fiocruz; 2010. p. 13-22.

12. Fagundes VO. Blogs de ciência. Comunicação, participação e as rachaduras na Torre de Marfim [dissertação na Internet]. Campinas: Universidade Estadual de Campinas; 2013 [citado em 2018 nov. 10]. Disponível em: http://repositorio.unicamp.br/jspui/handle/REPOSIP/270850

13. Fagundes VO. Ciência aberta e bactérias extraterrestres: transparência e colaboração na produção do conhecimento. Liinc em Rev. 2014 [citado em 2018 nov. 10];10(2):487-97. Disponível em: http://revista. ibict.br/liinc/article/view/3574/3062. doi: https://doi.org/10.18617/liinc.v10i2.729

14. Baram-Tsabari A, Lewenstein BV. Preparing scientists to be science communicators. In: Preparing informal science educators [Internet]. Cham: Springer International Publishing; 2017 [cited 2018 Nov 15]. p. 437-71. Available from: http://link.springer.com/10.1007/978-3-319-50398-1 22

15. European Commission. Science and society: action plan. Bruxelles: European Communities; 2002.

16. Massarani L, Moreira IC. Science communication in Brazil: a historical review and considerations about the current situation. An Acad Bras Cienc [Internet]. 2016 Aug 15 [citado em 2018 Nov 15];88(3):157795. Disponível em: https://bit.ly/2ZAZc8W. doi: http://dx.doi.org/10.1590/0001-3765201620150338

17. Rocha JN. Museus e centros de ciências itinerantes: análise das exposições na perspectiva da Alfabetização Científica [tese na Internet]. São Paulo: Universidade de São Paulo; 2018 [citado em 2019 janeiro 09]. Disponível em: https://bit.ly/2VgJct9

18. Ferreira JR. Popularização da ciência e as políticas públicas no Brasil (2003-2012) [tese na Internet]. Rio de Janeiro: Universidade Federal do Rio de Janeiro; 2014 [citado em 2019 jan. 09]. Disponível em: https://bit.ly/2GF9Rqz

19. Rocha JN. A cultura científica de professores da educação básica: a experiência de formação a distância na Universidade Aberta do Brasil - UFMG [dissertação na Internet]. Campinas: Universidade Estadual de Campinas; 2013 [citado em 2019 jan. 09]. Disponível em: http://repositorio.unicamp.br/jspui/handle/ REPOSIP/270718

20. Rocha JN. Museus e centros de ciências ameaçados no país. Cienc Cult [Internet]. 2017 mar [citado em 2019 jan. 09];69(1):14-5. Disponível em: https://bit.ly/2IzzgVY. doi: http://dx.doi.org/10.21800/2317$\underline{66602017000100007}$

21. Almeida C, Brito F, Ferreira JR, Massarani L, Amorim L. Centros e museus de ciência do Brasil. Rio de Janeiro: ABCMC; 2015. 312 p.

22. Rocha JN, Marandino M. Mobile science museums and centres and their history in the public communication of science. J Sci Commun [Internet]. 2017 July 20 [cited 2018 Nov 15]; 16(03). Available from: https://bit.ly/2UyWkFE. doi: https://doi.org/10.22323/2.16030204

23. Johnson RB, Onwuegbuzie AJ. Mixed methods research: a research paradigm whose time has come. Educ Res [Internet]. 2004 Oct [cited 2018 Nov 15];33(7):14-26. Available from: https://bit.ly/2Zjl3Bs. doi: https://doi.org/10.3102/0013189X033007014

24. Bardin L. Análise de conteúdo. Lisboa: Edições 70; 1977.

25. Brossard D, Lewenstein B V. A critical appraisal of models of public understanding of science: using practice to inform theory. In: Communicating science: new agendas in communication [Internet]. Routledge; 2010 [cited 2018 Nov 15]. p. 11-39. Available from: https://bit.ly/2UNf4X0. doi: https://doi. org/10.4324/9780203867631

26. Cottam H, Leadbeater C. Red paper 1: health: co-creating services [Internet]. London: Design Council; 2004 [citado em 2018 nov. 15]. 38 p. Disponível em: https://bit.ly/2UwjrAX

27. Abighannam N. Madam science communicator: a typology of women's experiences in online science communication. Sci Commun [Internet]. 2016 Ago 10 [cited 2018 Nov 15];38(4):468-94. Available from: http://journals.sagepub.com/doi/10.1177/1075547016655545

28. Johnson DR, Ecklund EH, Lincoln AE. Narratives of science outreach in elite contexts of academic science. Sci Commun [Internet]. 2014 Feb 16 [cited 2018 Nov 15];36(1):81-]105. Available from: http://journals. sagepub.com/doi/10.1177/1075547013499142 
29. Delicado A. Women in science communication. In: Encyclopedia of international higher education systems and institutions [Internet]. Dordrecht: Springer Netherlands; 2017 [cited 2019 Jan 5]. p. 1-3. Available from: https://doi.org/10.1007/978-94-017-9553-1 354-1

30. Jensen P. A statistical picture of popularization activities and their evolutions in France. Public Underst Sci [Internet]. 2011 Jan 13 [cited 2019 Jan 5];20(1):26-36. Available from: https://doi. org/10.1177/0963662510383632

31. Welde K de, Laursen S. The glass obstacle course: informal and formal barriers for women Ph.D. students in stem fields. Int J Gender, Sci Technol. 2011;3(3):571-95.

32. Andrews E, Weaver A, Hanley D, Shamatha J, Melton G. Scientists and public outreach: Participation, motivations, and impediments. J Geosci Educ. 2005;53(3):281-93.

33. Patiño ML, González JP, Massarani L. Diagnóstico de la divulgación de la ciencia en América Latina: una mirada a la práctica en el campo [Internet]. Ciudad de México: Fibonacci; 2017. [citado en 2019 ene. 5]. 144 p. Disponible: https://bit.ly/2tFajlZ

34. Moreira IC, Massarani L. Aspectos históricos da divulgação científica no Brasil. In: Ciência e Público: caminhos da divulgação científica no Brasil. Casa da Ciência/UFRJ; 2002. p. 43-64.

35. Massarani L. Comunicação da ciência e apropriação social da ciência: algumas reflexões sobre o caso do Brasil. Uni-pluri/versidad [Internet]. 2012 [citado em 2018 nov. 15];12(3):92-100. Disponível em: https://aprendeenlinea.udea.edu.co/revistas/index.php/unip/article/view/15161

36. Trench B. Towards an analytical framework of science communication models. In: Communicating science in social contexts [Internet]. Dordrecht: Springer Netherlands; 2008 [cited 2018 Nov 15]. p. 119-35. Available from: https://bit.ly/2IyPqyF

37. Wynne B. Public engagement as a means of restoring public trust in science: hitting the notes, but missing the music? Public Health Genomi [Internet]. 2006 [cited 2018 Nov 15]; 9(3):211-20. Available from: https://www.karger.com/Article/fulltext/92659. doi: https://doi.org/10.1159/000092659

38. Bauer MW. Results of the essay competition on the 'deficit concept.' Public Underst Sci [Internet]. 2016 May 26 [cited 2018 Nov 15]; 25(4):398-9. Available from: http://journals.sagepub.com/ doi/10.1177/0963662516640650

39. Bandelli A. Contextualizing visitor participation: european science centers as a platform for scientific citizenship [dissertation on the Internet]. Amsterdam: Vrije Universiteit; 2014. [cited 2019 Jan 05]. Available from: https://www.ecsite.eu/sites/default/files/dissertation bandelli.pdf

40. Pohlman D. Not so fast: some thoughts on re-visioning PUR. In: Creating connections Museums and the public understanding of current research. Walnut Creek: Altamira Press; 2004. p. 329-36.

41. Rocha JN, Gonçalves JC, Cordioli LA, Ferreira FB. Accesibilidad en museos, espacios científico-culturales y acciones de divulgación científica en Brasil. In: Aproximaciones a la investigación en divulgación de la ciencia en América Latina a partir de sus artículos académicos. San Luis: RedPop; 2017. p. 169-203.

42. Rocha JN, Massarani L, Gonçalves JC, Ferreira FB, de Abreu WV, Molenzani AO, et al. Guia de Museus e Centros de Ciências Acessíveis da América Latina e do Caribe [Internet]. Rio de Janeiro: Museu da Vida/Casa de Oswaldo Cruz/Fiocruz, RedPOP; 2017 [citado em 2018 nov. 15]. Disponível em: https:// grupomccac.org/publicacoes/

43. Bucchi M, Trench B. Science communication research: themes and challenges. In: Routledge handbook of public communication of science and technology. New York: Routledge; 2014. p. 1-13.

44. Marandino M, Rocha JN, Cerati TM, Scalfi G, Oliveira D, Lourenço MF. Ferramenta teórico-metodológica para o estudo dos processos de alfabetização científica em ações de educação não formal e comunicação pública da ciência: resultados e discussões. J Sci Commun América Lat [Internet]. 2018 nov 21 [citado em 2019 jan. 09];01(01). Disponível em: https://jcomal.sissa.it/archive/01/01/ JCOMAL 01012018 A03

45. European Commission. Call: science with and for society. European Commission; 2017. p. 75. 